\title{
GESTATIONAL TROPHOBLASTIC DISEASE - DEMOGRAPHIC, CLINICAL AND HISTOPATHOLOGICAL PROFILE AT A TERTIARY CARE HOSPITAL IN KASHMIR.
}

KEY WORDS: GTD,GTN, molar.

\section{Dr Asma Hassan Mufti*}

\section{Dr Lubna Rashid}

Senior Resident Department of Obstetrics and Gynecology, Goverment Medical College Srinagar, Kashmir, India. * Corresponding Author

Senior Resident Department of Obstetrics and Gynecology, Goverment Medical College Srinagar, Kashmir, India

BACKGROUND: Gestational trophoblastic disease encompasses a spectrum of tumors and tumor-like conditions characterized by abnormal proliferation of pregnancy associated trophoblastic tissues of varying abilities for invasion and spread. GTD lesions are histologically distinct and can be benign or malignant. Gestational trophoblastic neoplasms are now some of the most curable of all solid tumors, with cure rates of $90 \%$ even in the presence of widespread metastatic disease.

MATERIALS AND IMETHODS: It was a retrospective observational study carried out at the department of obstetrics and gynecology gmc srinagar. The demographic and clinical data as well as histopathology of all the consecutive patients with molar pregnancy admitted between January, 2019 and December, 2019 were retrieved and entered into prepared proformas.

RESULTS: Our study population included a total of 58 patients.The incidence in our study was $5.01 / 1000$ deliveries.Majority of patients in our study were in the age group of $20-30$ years i.e.48.3\%.58.6\% patients in our study population were illeterate while as most patients belonged to lower middle class i.e. $44.8 \% .24 .1 \%$ patients in our study were primigravida while as $55.2 \%$ had a previous term pregnancy.Maximum patients presented in first trimester i.e. $51.7 \%$. All patients in the study presented with a period of ammenorrhea followed by bleeding PV(72.4\%), hyperemesis $(44.8 \%)$ and passage of grape like vesicles(25.9\%). 3 patients had acute heamorrhagic shock on presentaion. Maximum patients $(84.4 \%)$ had USG documented molar pregnancy.Majority of patients( $88 \%)$ belonged to low risk as per FIGO staging. 37.9\% patients had blood group A while $32.8 \%$ had blood group B. On histopathology $50 \%$ patients had partial mole followed by complete mole in $38 \%$. Invasive mole was seen in $10.3 \%$ while choriocarcinoma accounted for $1.3 \%$.This study reported no case of PSTT.

CONCLUSION:GTNs are among the rare human tumours that can be cured even in the presence of widespread dissemination. Thus an early and accurate differential diagnosis is important for patient councelling and perinatal management but also for preservation of fertility.

\section{INTRODUCTION}

Gestational trophoblastic disease encompasses a spectrum of tumors and tumor-like conditions characterized by abnormal proliferation of pregnancy associated trophoblastic tissues of varying abilities for invasion and spread ${ }^{1-4}$. GTD lesions are histologically distinct and can be benign or malignant. Benign lesions include hydatidiform mole (complete and partial), whereas malignant lesions consist of invasive mole, placentalsite trophoblastic tumor and choriocarcinoma. This subset of malignant lesions that have varying propensities for local invasion and metastasis is referred to as gestational trophoblastic neoplasia.

Gestational trophoblastic neoplasms are now some of the most curable of all solid tumors, with cure rates of $90 \%$ even in the presence of widespread metastatic disease ${ }^{6,7,8}$. Broad variations in the incidence of GTD have been reported in different parts of the world ${ }^{9,10}$. Risk factors include extremes of reproductive age, multiparity, past history of spontaneous abortions, endogenous oestrogens, high beta carotene diet, high animal fat diet, ethnicity, ABO blood group, environmental toxins, smoking, alcohol consumption, socioeconomic status, herbicide exposure etc ${ }^{11,12}$.

GTNs are among the rare human tumours that can be cured even in the presence of widespread dissemination. Hydatidiform mole is a relatively common gynecological problem which could present like spontaneous abortion, one of the commonest gynecological emergencies.HMs are genetically abnormal, nonviable conceptions, which are associated with significantly increased risk for development of complications due to persistence of abnormal trophoblast (persistent GTN; pGTN), which occurs following $15 \%$ of CHM and $0.5 \%$ of PHM.

In case of partial mole, histologically a proportion of the villi are edematous with sometimes a central cistern (fig 1). Fetal vessels are usually present. Some enlarged villi may show a degree of trophoblastic hyperplasia but usually less marked than that seen in a complete mole. A complete mole on the otherhand forms often a bulky mass and has a classical bunch of grapes appearance. No normal placental tissue is apparent and all villi are enlarged, forming transparent vesicles of variable size (1 to $30 \mathrm{~mm}$ ) (fig 2). An embryo or fetus is absent.Histologically, all the villi are distended, edematous and often show central cisterns. Fetal vessels are generally absent. The villous trophoblast shows an irregular proliferation (hyperplasia), often associated with cytologic atypia.

From a clinical point of view, GTD is recognized today as the most curable gynecologic malignancy, for two major reasons:

1. Human chorionic gonadotropin (hCG) is produced by the various trophoblastic proliferations, and hCG concentration in the urine or serum is directly related to the number of viable trophoblastic cells. For this reason, hCG is a unique sensitive marker in the management of patients with GTD.

2. Proliferating trophoblast is extremely sensitive to certain chemotherapeutic agents, such as methotrexate and actinomycin D

Suction evacuation and curettage is the preferred method of evacuation of a hydatidiform mole, independent of uterine size, for patients who wish to maintain their fertility.Follow-up after evacuation of a hydatidiform mole is essential to detect trophoblastic sequelae (invasive mole or choriocarcinoma.

There is a clear clinical advantage for women to be informed about the diagnosis of molar pregnancy and their risk of developing placental cancer as quickly as possible so that adequate follow up can be initiated. Thus an early and accurate differential diagnosis is important for patient councelling and perinatal management but also for preservation of fertility ${ }^{13}$. Early diagnosis along with the 
chemosensitive nature of GTD and centralisation of care has resulted in survival rates of greater than $90 \%{ }^{14}$.

\section{MATERIALS AND METHODS}

It was a retrospective observational study carried out at the department of obstetrics and gynecology gmc srinagar. The demographic and clinical data as well as histopathology of all the consecutive patients with molar pregnancy admitted between January, 2019 and December, 2019 were retrieved and entered into prepared proformas.

Analysis of data was done using simple percentages. The number of deliveries during the study period was obtained from the labour ward register.

\section{RESULTS}

Out of total 11569 deliveries during the study period, 58 patients were diagnosed with GTD. Thus the incidence in our study was 5.01/1000 deliveries.

\begin{tabular}{|c|c|l|}
\hline Total deliveries & No. Of patients with GTD & Incidence \\
\hline 11569 & 58 & $5.01 / 1000$ \\
\hline
\end{tabular}

So our study population included a total of 58 patients.

\begin{tabular}{|l|l|l|}
\hline AGE(years) & No. Of patients & $\%$ \\
\hline$<20$ & 9 & 15.5 \\
\hline $20-30$ & 28 & 48.3 \\
\hline$>30$ & 21 & 36.2 \\
\hline
\end{tabular}

Majority of patients in our study were in the age group of 20-30 years i.e.48.3\%.

\begin{tabular}{|l|l|l|}
\hline SOCIOECONOMIC STATUS & No. Of Patients & $\%$ \\
\hline Lower Class & 17 & 29.3 \\
\hline Lower Middleclass & 26 & 44.8 \\
\hline Upper Middleclass & 15 & 25.9 \\
\hline
\end{tabular}

Most patients belonged to lower middle class (44.8\%) in our study.

\begin{tabular}{|l|l|l|}
\hline LITERACY & No. Of Patients & $\%$ \\
\hline Literate & 24 & 41.4 \\
\hline Illiterate & 34 & 58.6 \\
\hline
\end{tabular}

$58.6 \%$ patients in our study population were illeterate.

\begin{tabular}{|l|l|l|}
\hline ANTECEDENT PREGNANCY & NO. OF PATIENTS & $\%$ \\
\hline Mole & 3 & 5.2 \\
\hline Abortion & 9 & 15.5 \\
\hline Term & 32 & 55.2 \\
\hline $1^{\text {St }}$ Pregnancy & 14 & 24.1 \\
\hline
\end{tabular}

$24.1 \%$ patients in our study were primigravida while as $55.2 \%$ had a previous term pregnancy.

\begin{tabular}{|l|l|l|}
\hline GESTATIONAL AGE(weeks) & NO. OF PATIENTS & $\%$ \\
\hline$<14$ & 30 & 51.7 \\
\hline $14-20$ & 21 & 36.2 \\
\hline$>20$ & 7 & 12.1 \\
\hline
\end{tabular}

Maximum patients in our study presented in first trimester i.e. $51.7 \%$.

\begin{tabular}{|l|l|l|}
\hline PRESENTING SYMPTOMS & NO. OF PATIENTS & $\%$ \\
\hline Ammenorrhea & 58 & 100 \\
\hline Bleeding PerVaginum & 42 & 72.4 \\
\hline Passage Of Grape Like Vesicles & 15 & 25.9 \\
\hline Hyperemesis & 26 & 44.8 \\
\hline Thyrotoxicosis & 9 & 15.5 \\
\hline Theca Lutein Cysts & 7 & 12.1 \\
\hline $\begin{array}{l}\text { Usg Documented } \\
\text { Molar Pregnancy }\end{array}$ & 49 & 84.4 \\
\hline Acute Heamorrhagic Shock & 3 & 5.2 \\
\hline
\end{tabular}

All patients in the study presented with a period of ammenorrhea followed by bleeding PV(72.4\%), hyperemesis $(44.8 \%)$ and passage of grape like vesicles $(25.9 \%) .3$ patients had acute heamorrhagic shock on presentaion.Maximum patients (84.4\%) had USG documented molar pregnancy.

|www.worldwidejournals.com|

\begin{tabular}{|l|l|l|}
\hline PRE TREATMENT B HCG LEVEL & NO .OF PATIENTS & $\%$ \\
\hline$<50,000$ & 18 & 31 \\
\hline $50,000-1$ Lac & 25 & 43.1 \\
\hline$>1$ LaC & 15 & 25.9 \\
\hline
\end{tabular}

Pre treatment B HCG was between 50,000-1 LAC in 43.1\%.

FIGOSTAGING

\begin{tabular}{|l|l|l|}
\hline RISK STRATIFICATION & NO.OF PATIENTS & $\%$ \\
\hline Low Risk & 51 & 88 \\
\hline High Risk & 7 & 12 \\
\hline
\end{tabular}

Majority of patients(88\%) belonged to low risk as per FIGO staging.

\begin{tabular}{|c|l|l|}
\hline BLOOD GROUP (ABO TYPE) & NO. OF PATIENTS & $\%$ \\
\hline A & 22 & 37.9 \\
\hline B & 19 & 32.8 \\
\hline$A B$ & 8 & 13.8 \\
\hline O & 9 & 15.5 \\
\hline
\end{tabular}

$37.9 \%$ patients had blood group A while $32.8 \%$ had blood group B.

\begin{tabular}{|l|l|l|}
\hline TYPE OF GTD ON HISTOPATHOLOGY \\
\hline GTD & NO. OF PATIENTS & $\%$ \\
\hline PARTIAL MOLE & 29 & 50 \\
\hline COMPLETE MOLE & 22 & 38 \\
\hline INVASIVE MOLE & 6 & 10.3 \\
\hline CHORIOCARCINOMA & 1 & 1.7 \\
\hline PSTT & 0 & 0 \\
\hline
\end{tabular}

On histopathology $50 \%$ patients had partial mole followed by complete mole in $38 \%$. Invasive mole was seen in $10.3 \%$ while choriocarcinoma accounted for $1.3 \%$.Single patient with choriocarcinoma was a 32 year, multipara who presented with amenorrhea and bleeding per vaginum. Her pre-treatment serum beta hCG level was 15,14,780 mIU/ml. Her blood group was $O$ positive. This study reported no case of PSTT.

\section{DISCUSSION}

Gestational trophoblastic disease (GTD) comprises a group of disorders spanning the premalignant conditions of complete and partial molar pregnancies through to the malignant conditions of invasive mole, choriocarcinoma and the very rare placental site trophoblastic tumour (PSTT) and epithelioid trophoblastic tumour (ETT).

Incidence of GTD varies widely throughout the world. It is reported greatest in Asia, Africa, and Latin America and substantially lower in North America, Europe, and Australia $15,16,17$. The incidence in our study was $5.01 / 1000$ deliveries which was similar to a study done by Sekharan $\mathrm{P}$ et al $\mathrm{l}^{18}$. A study done by Yakasai I et al. at Nigeria, showed incidence of GTD was 4.5, Agrawal N et al., 4.17, Koirala A et al., 3.94 per 1000 deliveries $^{19,20,21}$.

Majority of patients(48.3\%) in our study belonged to age group of 20-30 years. Study by Taboo ZA showed peak incidence of GTD was among 20-25 years age group which was similar to study by Kumar $\mathrm{N}$ et al having majority of GTD patients in age group of $20-25$ years comprising $66 \%{ }^{22,23}$.

Most of patients in our study group were illiterate (58.6\%) and of low socioeconomic status (74.1\%).

$24.1 \%$ patients in our study were primigravida .while a study conducted by Sunil et al showed $44.15 \%$ patients to be primi gravida $^{24}$.

Most of the cases presented in this study were in first trimester(51.7\%).Similar observations were found in studies done by Taboo et al and Sunil et $\mathrm{al}^{22,24}$.

All patients in the study group presented with a period of ammeorrhea followed by bleeding per vaginum(72.4\%), hyperemesis $(44.8 \%)$ and passage of grape like vesicles 
$(25.9 \%)$, and thyrotoxic symptoms in (15.5\%). 3 patients presented with acute heamorrhagic shock which accounted for $5.2 \%$ of study group.In the study by Sunil et al most common presentation was bleeding per vagina with $(94.80 \%)$ cases, followed by amenorrhea $(92.0 \%)^{24}$. Similar results were in agreement with other studies, like Taboo $\mathrm{Za}^{22}$.

WHO prognostic scoring system for GTD has included ABO blood groups one of the prognostic factor. If female and male partner are with blood group either $\mathrm{O}$ or $\mathrm{A}, \mathrm{A}$ or O; it carries better prognosis when compared with female having blood group $\mathrm{B}$ or $\mathrm{AB}^{25}$. Present study showed high incidence of GTD in patients with blood group 'A' followed by blood group 'O' and least were noted in blood group 'AB'.Majority of patients had pre treatment b HCG levels between 50,000 and 1 lac .While as $88 \%$ patients belonged to low risk group as per FIGO risk stratification.

Majority of GTD on histopathology in our study were hydatidiform mole comprising $88 \%$ of cases out of which $50 \%$ were partial mole (fig 1) and $38 \%$ were complete mole(fig 2).Similar results were found in study by Taboo ZA et al ,Kumar $\mathrm{N}$ et al and Sunil et al ${ }^{22,23,24}$. Invasive mole was seen in $10.3 \%$ while choriocarcinoma accounted for $1.3 \%$ (fig 3) .Single patient with choriocarcinoma was a 32 year, multipara who presented with amenorrhea and bleeding per vaginum. Her pre-treatment serum beta hCG level was 15,14,780 $\mathrm{mIU} / \mathrm{ml}$. Her blood group was $\mathrm{O}$ positive.PSTTs are very rare tumours. This study reported no case of PSTT.

The standard treatment for women who wish to have children in the future is to eliminate the mole by suction Dilation and Curettage (D\&C). Women who no longer wish to have children may be able to have a hysterectomy and for tumours requires chemotherapy ${ }^{26}$.

\section{Fig l(partial m}

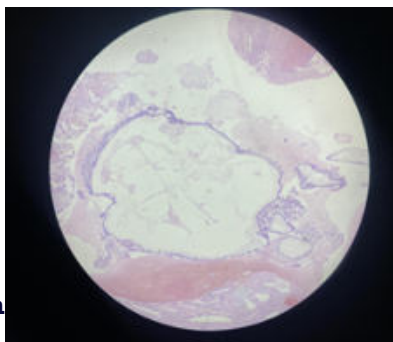

2(complete mo
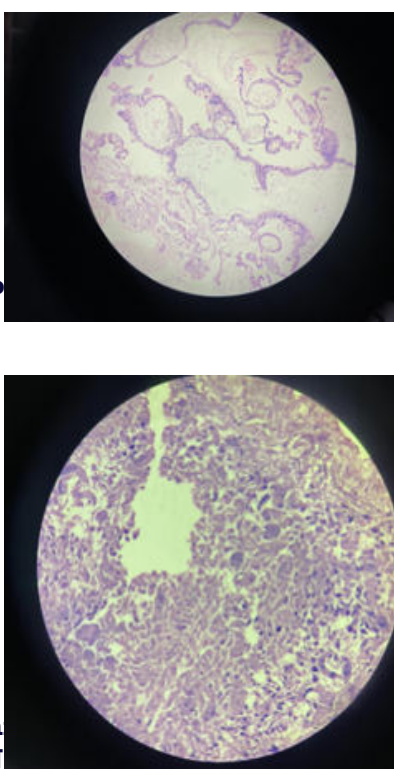

Fig 3 (chorioca CONCLUSION

The history of management of gestational trophoblastic disease (GTD) can be considered as one of the success stories of modern medicine as the majority, if not all, are potentially curable with the retention of reproductive function, once the correct diagnosis is made and treatment is commenced early enough.More research is needed in this regard.

\section{REFERENCES}

1. Mbamara SU, Obiechina NJA, Eleje GU, Akabuike CJ, Umeononihu OS Gestational Trophoblastic Disease in a Tertiary Hospital in Nnewi, Southeast Nigeria.Niger Med J.2009;50(4):87-9.

2. Nevin J, Bloch B, Dehaeck K, Soeters R. Gestational tropiblastic disease.Manual of Practical Gynaecological Oncology. London: Chapman and Hall; 1995.p. 130-46.

3. Berkowitz RS, Goldstein DP. Molar Pregnancy. N Engl J Med. 2009; 360: 16 3945.

4. Moore LE, Hernandez E. Hydatidiform Mole [Internet]. Medscape Reference,Web MD LLC. 2014 [cited 2014 Dec 10]. Available from: http:// emedicine.medscape.com/article/254657-overview.

5. Seckl MJ, Sebire NJ, Berkowitz RS. Gestational trophoblastic disease. Lancet. 2010;376(9742):717-29.

6. Hancock BW, Seckl MJ, Berkowitz RS, Cole LA, eds. Gestational trophoblastic disease, 3rd ed. London, UK: International Society for the Study of Trophoblastic Diseases; 2009

7. Soper JT. Gestational trophoblastic disease. Obstet Gynecol 2006;108:17687

8. Berkowitz RS, Goldstein DP. Current management of gestational trophoblastic disease. Gynecol Oncol 2009;112:654-62.19

9. Palmer JR. Advances in the epidemiology of gestational trophoblastic disease. Journal Report Medical. 1994;39:155-62.

10. Lurain JR. Gestational trophoblastic disease: epidemiology, pathology, clinical presentation and diagnosis of gestational trophoblastic disease, and management of hydatidiform mole. Am J Obstet and Gynecol. 2010;203 (6) 531-39.

11. Deep JP, Sedhai LB, Napit J, Pariyar J. Gestational trophoblastic disease. J Chitwan Medical College. 2013;3(4):4-11.[5]

12. Berkowitz RS, Goldstein DP. In: Berck JS. Gestational trophoblastic neoplasm. Philadelphia,Lipincott,Williams andWilkins, 2002;1353-74.

13. Dhanda s,ramani s, thakur m. gestational trophoblastic disease:a multimodal imaging approach with impact on diagnosis and management. Radiol Res Pract 2014:84257(epub).

14. Froeling FEM, seckle mf, gestational trophoblastic tumours, an update for 2014.Curr Oncol Rep.2014;16:408.

15. Deep JP, Sedhai LB, Napit J, Pariyar J. Gestational trophoblastic disease. J Chitwan Medical College. 2013;3(4):4-11

16. Berkowitz RS, Goldstein DP. In: Berck JS. Gestational trophoblastic neoplasm. Philadelphia,Lipincott,Williams andWilkins,2002;1353-74.

17. Aziz MF, Kampono N, Moigni EM. Epidemiology of gestational trophoblastic neoplasia at the Dr. Cipto Mangukusmo Hospital Jakarta, Indonesia. Adv Exp Med Biol. 1984;176:165-75

18. Sekharan P, Shreedevi NS, Paily VP. Hydatidiform mole in Calicut, India. Proc XIIWorld Congr Gestation Trophobla Dis. Boston. 2003.

19. Yakasai I, Abubakar I, Eze Y. Gestational trophoblastic disease in a teaching hospital in Northern Nigeria. Am J Bio Sci. 2015;3(1):7-10.

20. Agrawal N, Sagtani RA, Budhathoki SS, Pokhare HP. Clinicopathological profile of molar pregnancies in a tertiary care centre of Eastern Nepal: a retrospective review of medical records. Gynecol Oncol Res Pract. 2015;2:912.

21. Koirala A, Khatiwada P, Giri A, Kandel P, Regmi M, Upreti D.The demographics of molar pregnancies in BPKIHS. Kathmandu Univ Med J KUMJ. 2011 ;9 (36): 298-300

22. Taboo ZA. A prospective study of gestational trophoblastic disease in AlMosul City.The Iraqi Post-graduate Medical Journal.2013;12(2):268-76.

23. Kumar N, Saxena YK, Rathi AK, Chitra R, Kumar P. Host and risk factors for gestational trophoblastic disease: a hospital based analysis from India. Med Sci Mohit Int Med JExp Clin Res. 2003:9(10):442-47

24. Sunil Vitthalrao Jagtap et al., Gestational Trophoblastic Disease,Journal of Clinical and Diagnostic Research. 2017 Aug,Vol-1 1(8):EC27-EC30.

25. Singh N, Singh U, Srivastav S. Prospective and retrospective analysis of gestational trophoblastic disease over a period of 5 years. J South Asian Federation of Obst and Gynec. 2013:5(1):11-14

26. Kenny L, Seckl MJ. treatments for gestational trophoblastic disease. Expert Rev of Obstet Gynecol. 2010;5,2:215-25. 